\title{
Interrupting oral infection of Porphyromonas gingivalis with anti-FimA antibody attenuates bacterial dissemination to the arthritic joint and improves experimental arthritis
}

\author{
Sang Hoon Jeong ${ }^{1}$, Yoojun Nam ${ }^{1}$, Hyerin Jung ${ }^{1}$, Juryun Kim ${ }^{1}$, Yeri Alice Rim ${ }^{1}$, Narae Park ${ }^{1}$, Kijun Lee ${ }^{1}$, \\ Seungjin Choi ${ }^{1}$, Yeonsue Jang ${ }^{1}$, Yena Kim ${ }^{1}$, Ji-Hoi Moon ${ }^{2}$, Seung Min Jung ${ }^{1}$, Sung-Hwan Park ${ }^{1}$ and \\ Ji Hyeon $\mathrm{Ju}^{1}$
}

Rheumatoid arthritis (RA) is a chronic autoimmune disease that typically results in strong inflammation and bone destruction in the joints. It is generally known that the pathogenesis of RA is linked to cardiovascular and periodontal diseases. Though rheumatoid arthritis and periodontitis share many pathologic features such as a perpetual inflammation and bone destruction, the precise mechanism underlying a link between these two diseases has not been fully elucidated. Collagen-induced arthritis (CIA) mice were orally infected with Porphyromonas gingivalis (Pg) or Pg preincubated with an anti-FimA antibody (FimA Ab) specific for fimbriae that are flexible appendages on the cell surface. Pg-infected CIA mice showed oral microbiota disruption and increased alveolar bone loss and had synovitis and joint bone destruction. However, preincubation with FimA Ab led to a significant reduction in the severity of both oral disease and arthritis. Moreover, FimA Ab attenuated bacterial attachment and aggregation on human gingival and rheumatoid arthritis synovial fibroblasts. In addition, we discovered bacteria may utilize dendritic cells, macrophages and neutrophils to migrate into the joints of CIA mice. These results suggest that disrupting Pg fimbriae function by FimA Ab ameliorates RA.

Experimental \& Molecular Medicine (2018) 50, e460; doi:10.1038/emm.2017.301; published online 23 March 2018

\section{INTRODUCTION}

Rheumatoid arthritis (RA) is a chronic autoimmune disease that causes joint swelling, deformity and dysfunction. ${ }^{1}$ The actual factors that cause RA are unknown, but several genetic, physiological and environmental factors have been implicated. Despite the different pathogenic mechanisms, epidemiological data show that RA and periodontitis have similar pathological outcomes that include bone loss and destructive inflammation. ${ }^{2}$ Some clinical studies suggest that patients with RA are more likely to have periodontitis than healthy individuals. ${ }^{3-5}$ In addition, periodontitis is often accompanied by RA.6,7 Taken together, these data suggest a significant association between periodontitis and RA.

Porphyromonas gingivalis (Pg), a Gram-negative anaerobic bacterial pathogen, is the leading cause of periodontal disease in humans. Pg utilizes fimbriae, the appendages that grow out of the membrane, to invade host cells such as human gingival fibroblasts (HGFs). ${ }^{8,9}$ Fimbriae express one of two protein types according to their size. Long fimbriae, also known as major fimbrilin, comprise FimA subunit proteins encoded by the fimA gene. ${ }^{8}$ With regard to fimbriae, some experimental studies show that Pg harboring mutations in FimA fail to form biofilms. ${ }^{10}$ Studies in a gnotobiotic rat model show that Pg strain DPG3 (a FimA mutant) cannot bind to saliva-coated oral surfaces nor cause alveolar bone loss. ${ }^{11}$ In addition, infection of mouse peritoneal macrophages with purified major fimbriae induces the expression of interleukin-1 (IL-1). ${ }^{12}$ Therefore, Pg fimbriae are a key component of adhesion to host surfaces during periodontal disease.

Oral infection by Pg worsens paw swelling, bone loss and synovitis, and increases proinflammatory cytokine expression

\footnotetext{
${ }^{1}$ Division of Rheumatology, Department of Internal Medicine, Seoul St. Mary's Hospital, College of Medicine, The Catholic University of Korea, Seoul, South Korea and ${ }^{2}$ Department of Maxillofacial Biomedical Engineering, School of Dentistry, and Department of Life and Nanopharmaceutical Sciences, Kyung Hee University, Seoul, South Korea

Correspondence: Professor JH Ju, Division of Rheumatology, Department of Internal Medicine, Seoul St. Mary's Hospital, College of Medicine, The Catholic University of Korea, 222 Banpo-Daero, Seocho-Gu, Seoul 137-701, South Korea.
}

E-mail: juji@catholic.ac.kr

Received 17 February 2017; revised 29 August 2017; accepted 26 September 2017 
in collagen-induced arthritis (CIA) and collagen antibodyinduced arthritis mouse model. ${ }^{13,14}$ In rats, Pg causes signs and symptoms associated with arthritis, whereas heat-killed Pg does not. ${ }^{15}$ Although periodontal disease induced by Pg infection is thought to be associated with RA pathogenesis, the contribution of fimbriae is largely unknown.

Here, we examined the pathogenic and therapeutic correlation between periodontitis and RA in a mouse model of arthritis. Studies suggest that Pg-induced periodontitis plays a significant role in RA development. Inhibiting Pg adhesion using a FimA antibody (Ab) prevented RA progression. We also showed that orally inoculated Pg may utilize dendritic cells (DCs), macrophages and neutrophils to migrate to the joints of CIA mice and result in synovial inflammation.

\section{MATERIALS AND METHODS}

\section{Mice and in vivo study design}

The 5-week-old female DBA1/J mice were obtained from OrientBio (Seongnam, Korea) and quarantined for 1 week in the pathogen-free animal facility at the Catholic University of Korea. All animal experiments were performed in accordance with the Laboratory Animals Welfare Act, Guide for the Care and Use of Laboratory Animals and Guidelines and Policies for Rodent Experimentation provided by the Institutional Animal Care and Use Committee at the School of Medicine at the Catholic University of Korea. The study utilized six experimental groups, each containing five mice.

\section{Antibody}

The monoclonal FimA Ab was provided by NBM (Jeonju, Korea). The $\mathrm{Ab}$ was synthesized and characterized as previously described. ${ }^{16,17}$

\section{Bacteria strain}

Pg strain 2561 was obtained from the Department of Maxillofacial Biomedical Engineering, School of Dentistry, Kyung Hee University, Seoul, Korea. The bacterium was cultured at $37^{\circ} \mathrm{C}$ anaerobically $(85 \%$ $\mathrm{N}_{2}, 10 \% \mathrm{H}_{2}$ and $5 \% \mathrm{CO}_{2}$ ) in half-strength brain heart infusion broth (Becton Dickinson, Sparks, MD, USA) supplemented with $0.5 \%$ yeast extract (Difco Laboratories, Detroit, MI, USA), $5 \mu \mathrm{g} \mathrm{ml}^{-1}$ hemin (Sigma-Aldrich, St Louis, MO, USA) and $1 \mu \mathrm{g} \mathrm{ml}^{-1}$ vitamin $\mathrm{K} 1$ (Sigma-Aldrich).

\section{Induction of periodontitis}

To increase the rate of bacterial infection, mice were inoculated with $5 \times 10^{9}$ colony-forming units in $50 \mu$ l of phosphate-buffered saline with $2 \%$ carboxylmethyl cellulose (Sigma-Aldrich). Bacteria were inoculated directly into the oral cavity every day for 15 days using a disposable pipette. A previous study shows that FimA Ab inhibits the adhesive activity of major fimbriae from Pg. ${ }^{16}$ Therefore, before inoculation, $5 \times 10^{9}$ colony-forming units of Pg were incubated with $500 \mathrm{ng}$ of FimA Ab in phosphate-buffered saline for $1 \mathrm{~h}$. It was then resuspended in $50 \mu \mathrm{l}$ of phosphate-buffered saline with $2 \%$ carboxylmethyl cellulose.

\section{Assessment of periodontitis}

The total anaerobic bacteria count was determined using the McFarland turbidity standard protocol. Bacteria were directly swabbed from the gingival surface of CIA mice using a small sterilized brush, and then soaked in tryptic soy broth medium (Difco Laboratories, Detroit, MI, USA), and incubated in an anaerobic basket with an anaerobic gas pack (AnaeroGen, Oxoid, Hampshire, UK). Alveolar bone loss was examined morphometrically by measuring the distance between the cementoenamel junction (CEJ) and alveolar bone crest (ABC), as previously described. ${ }^{18,19}$ Briefly, skulls were first autoclaved and defleshed, and the jaws were immersed in 3\% hydrogen peroxide overnight and then stained with $1 \%$ methylene blue for $1 \mathrm{~min}$. The distance from the CEJ to the $\mathrm{ABC}$ was assessed at five buccal sites per mouse using the Visiopharm Integrator System (Visiopharm, Horsholm, Denmark). All data were analyzed using GraphPad Prism 5 software (GraphPad, San Diego, CA, USA).

\section{Induction of CIA}

Mice were shaved, and the back was injected intradermally with CII emulsified in complete Freund's adjuvant containing $2 \mathrm{mg} \mathrm{ml}^{-1}$ heatkilled mycobacterium tuberculosis. To maximize the incidence of periodontitis-induced arthritis, mice did not receive a second immunization with CII. The arthritis clinical score was measured every week for 44 days after CII immunization. Each limb was scored on a scale of $0-4$ as follows: $0=$ normal; $1=$ slight swelling; $2=$ pronounced swelling; $3=$ severe swelling without joint deformation; and $4=$ joint deformation accompanied by ankyloses. The scores for all four limbs were summed, giving a maximum of 16 points per animal. Each score was determined by three independent examiners.

\section{Immunohistochemical analysis}

Both hind limbs from each mouse were retrieved and fixed in 10\% formalin, decalcified in $10 \%(\mathrm{w} / \mathrm{v})$ EDTA and embedded in paraffin. Sections were stained with hematoxylin and eosin, safranin $\mathrm{O}$ or toluidine blue for histological analysis. Inflammation and joint destruction were scored by three individual observers.. ${ }^{20}$ The inflammation score was assessed on the basis of the immune cell infiltration and pannus formation. Joint destruction was scored according to alterations in cartilage erosion and bone loss.

\section{Micro-computed tomography (micro-CT) analysis}

Hind limb samples were obtained, fixed in $10 \%$ formalin, and scanned in a micro-CT scanner (SkyScan 1172, SkyScan b.v.b.a., Aartselaar, Belgium). Images were reconstructed using NRecon V1.6.9.18 (SkyScan). Three-dimensional analysis was performed using CTAn software (SkyScan).

\section{Confocal microscopy}

Joint sections were stained with aFimA $\mathrm{Ab}$ using the VECTOR M.O.M. Immunodetection Kit (Vector Laboratories, Burlingame, CA, USA), according to the manufacturer's protocol. DCs were stained with anti-CD11c Ab (Serotec, Oxford, UK) and Alexa Fluor 568-conjugated goat anti-American hamster Ab (Abcam, Cambridge, MA, USA). Neutrophils and macrophages were stained with antiNIMP-R14 Ab (Abcam) and anti-F4/80 Ab (eBioscience, San Diego, CA, USA), respectively, followed by Texas Red goat anti-rat Ab (Vector Laboratories). To stain the blood vessel, the joint sections were stained with anti-CD31 Ab (Santa Cruz Biotechnology, Santa Cruz, CA, USA) and Fluorescein rabbit anti-goat Ab (Vector Laboratories). Toll like receptor-2 (TLR2) and TLR4 were stained with anti-TLR2 Ab (Santa Cruz) and anti-TLR4 Ab (Santa Cruz), respectively, followed by Fluorescein rabbit anti-goat $\mathrm{Ab}$ (Vector Laboratories) in the joint sections. Fluorescence images were obtained under a confocal microscope (Carl Zeiss LSM 700, Prenzlauer, Berlin, Germany). 


\section{Cell strains}

HGF-1 cells were purchased from American Type Culture Collection (Manassas, VA, USA). Rheumatoid arthritis synovial fibroblasts (RASFs) were obtained from synovial tissue from RA patients as previously described, ${ }^{21}$ in accordance with the protocols approved by the institutional review board of The Catholic University of Korea.

\section{Immunofluorescence analysis}

Cultured cells were fixed in $3.7 \%$ formaldehyde for $10 \mathrm{~min}$, immersed in $0.1 \%$ Triton $\mathrm{X}-100$ for $5 \mathrm{~min}$ at $4{ }^{\circ} \mathrm{C}$, blocked with $2 \%$ bovine serum albumin (Sigma-Aldrich) for $1 \mathrm{~h}$ at $37^{\circ} \mathrm{C}$ and then incubated with FimA Ab for $1 \mathrm{~h}$ at $37^{\circ} \mathrm{C}$ in phosphate-buffered saline containing $1 \%$ bovine serum albumin and $0.1 \%$ Triton X-100. Cells were then incubated with an Alexa Flour 488-conjugated mouse antibody (Molecular Probes, Eugene, OR, USA). Nuclei were stained with 4',6-diamidino-2-phenylindole (Molecular Probes). Intracellular protein expression was examined under a fluorescence microscope (Axio Imager.M2; Zeiss, Oberkochen, Germany).

\section{Electron microscopy}

Hind limbs of CIA mice were fixed in $4 \%$ paraformaldehdyde and immersed in $2.5 \%$ glutaraldehyde in $0.1 \mathrm{M}$ phosphate buffer for overnight. The samples were post-fixed with $1 \%$ osmium tetroxide for $1 \mathrm{~h}$. For transmission electron microscopic observations, the samples were dehydrated with a series of the graded ethyl alcohol and pure acetone. After embedding in Epon 812, ultrathin sections $(60-70 \mathrm{~nm})$ were obtained by ultramicrotome (Leica Ultracut UCT, Wetzlar, Germany). Ultrathin sections collected on grids (200 meshes) were examined in transmission electron microscope (JEOL-JEM 1010, JEOL Co., Ltd., Tokyo, Japan) operating at $60 \mathrm{kV}$ and images in the transmission electron microscopy were recorded by CCD camera (SC1000; Gatan, Pleasanton, CA, USA). For scanning electron microscopic observations, the samples were dehydrated in ascending concentration of ethyl alcohol from 50 to $100 \%$ (12 h at each concentration) and then transferred to hexametyldisilazane and allowed to air dry. All samples were coated with gold using a sputter coater and examined on a JSM-5410LV (JEOL, Tokyo, Japan) scanning electron microscope operated with accelerating voltage of $15 \mathrm{kV}$.

\section{Real-time PCR}

Before Pg treatment of RASFs, Pg was incubated with $100 \mathrm{ng} \mathrm{ml}^{-1}$ aFimA for $1 \mathrm{~h}$ in growth medium. After then, RASFs were treated with $\mathrm{Pg}$ or Pg/FimA for various time periods. RNA was then extracted from cells using TRIzol (Invitrogen, Carlsbad, CA, USA) reagent. Complementary DNA was synthesized using HelixCript Easy cDNA Kit (Nano Helix, Seoul, Korea). Real-time PCR was performed in ABI 7500 system (Applied Biosystems, Foster City, CA, USA) with SYBR green (Nano Helix). Primer sequences are listed in Supplementary Table S1. a

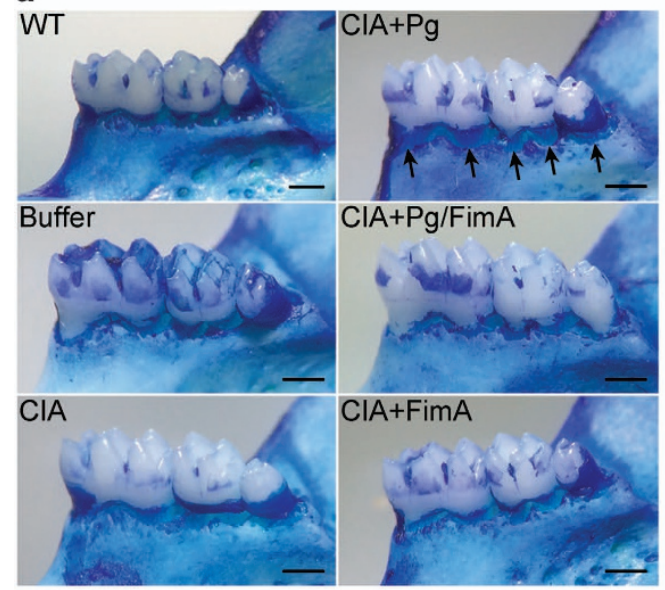

C

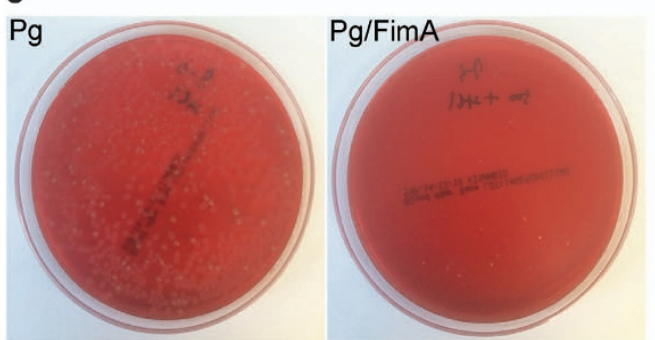

b

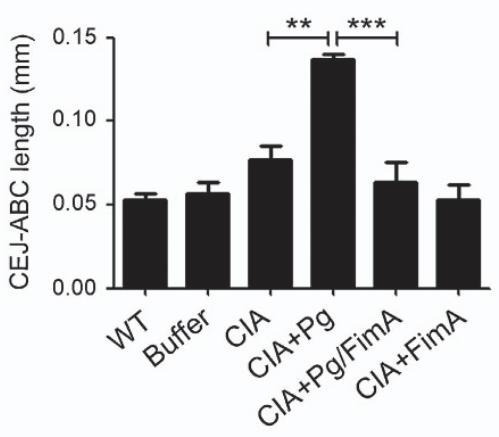

d

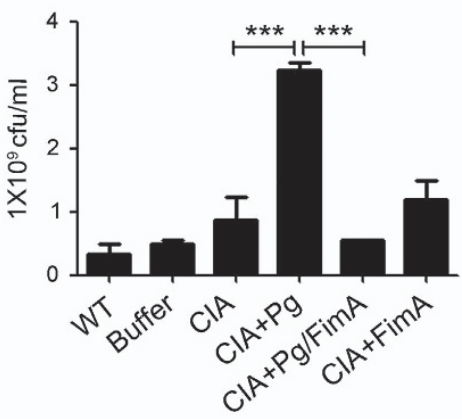

Figure 1 Anti-FimA antibody (aFimA Ab) inhibits Porphyromonas gingivalis (Pg)-induced periodontitis in collagen-induced arthritis (CIA) mice. (a) The cementoenamel junction-alveolar bone crest (CEJ-ABC) length in low jaw bone is detected by optical microscope. Scale bar, $1 \mathrm{~mm}$. (b) Scoring of CEJ-ABC length is randomly measured at five buccal sites of low jaw bone (arrows of (a)) and analyzed using Student's $t$-test $\left({ }^{* *} P<0.01,{ }^{* *} P<0.001\right)$. (c) Collected bacteria using swab from the oral cavity of mice are grown on sheep blood agar. (d) The number of total cultivatable oral anaerobic bacteria is analyzed using McFarland turbidity standards. Oral swabs were collected from mice and cultivated under anaerobic condition. Statistical analysis was performed using Student's $t$-test $(n=3, * * * P<0.001)$. 
a

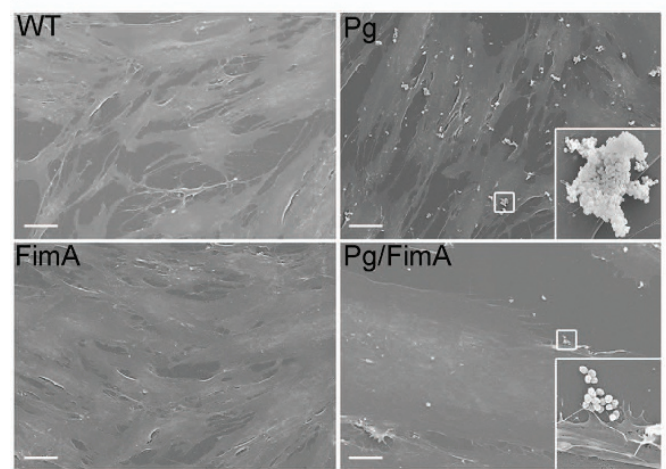

C

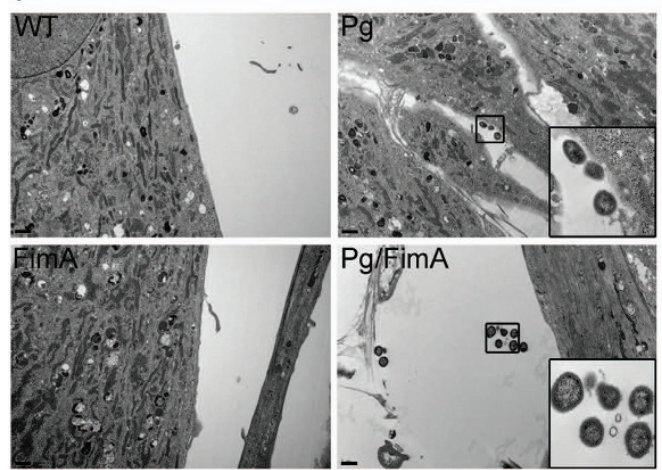

b

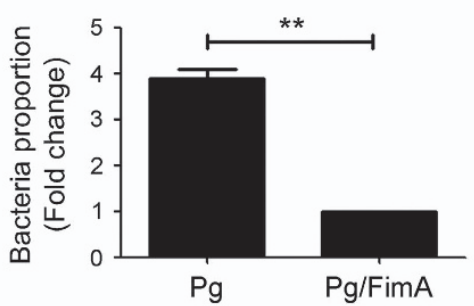

d

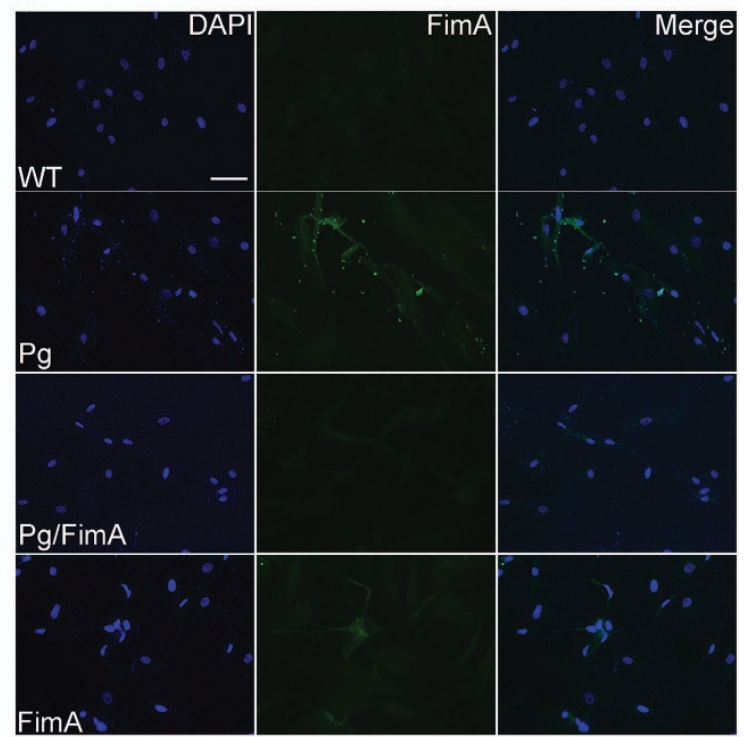

Figure 2 Fimbriae play an essential role in Porphyromonas gingivalis (Pg) invasion. (a-c) Bacteria adhesion to the human gingival fibroblast-1 (HGF-1) after infection of Pg with or without pretreatment of anti-FimA antibody (aFimA Ab) is observed by scanning electron microscopy (SEM) and transmission electron microscopy (TEM), respectively. Scale bar, $100 \mu \mathrm{m}$ (a) and $1 \mu \mathrm{m}$ (c). Inserts magnify the small box areas. (b) Quantification of bacteria proportion in SEM images. Statistical analysis was performed using Student's $t$-test $(n=3$, ${ }^{*} P<0.01$ ). (d) Immunohistochemical staining of FimA (green) in HGF-1 also shows the attenuation of bacteria adhesion in aFimA Abtreated Pg. Cell nuclei are stained with 4',6-diamidino-2-phenylindole (DAPI; blue). Scale bar, $100 \mu \mathrm{m}$.

\section{Preparation of crude fimbriae}

Pg was harvested by centrifugation at $90 \mathrm{~g}$ for $40 \mathrm{~min}$ at $4{ }^{\circ} \mathrm{C}$, and the pellet was suspended in $5 \mathrm{~mm}$ Tris- $\mathrm{HCl}$ buffer, followed by sonication for $3 \times 5 \mathrm{~min}$. After centrifugation at $18000 \mathrm{~g}$ for $40 \mathrm{~min}$, the supernatant was suspended in $40 \%$ ammonium sulfate for $4 \mathrm{~h}$. The sediment was then collected by centrifugation at $18000 \mathrm{~g}$ for $30 \mathrm{~min}$ at $4{ }^{\circ} \mathrm{C}$ followed by dialysis in $5 \mathrm{~mm}$ Tris- $\mathrm{HCl}$ for 3 days. After dialysis, crude fimbriae were collected by centrifugation at $900 \mathrm{~g}$ for $10 \mathrm{~min}$ at $4{ }^{\circ} \mathrm{C}$.

\section{Statistical analysis}

Statistical analyses were performed using GraphPad Prism 5 software (San Diego, CA, USA). Statistical differences between groups were analyzed using the paired $t$-test and one-way analysis of variance. The results of the in vitro studies were also analyzed using one-way analysis of variance. A $P$-value of $<0.05$ was considered statistically significant.

\section{RESULTS}

The FimA Ab inhibits periodontitis induced by Pg infection To study the ability of FimA Ab to prevent Pg oral infection, Pg was incubated in the presence or absence of FimA Ab before oral inoculation. Infection with $\mathrm{Pg}$ resulted in increase of the distance from the cementoenamel junction to the alveolar bone crest (CEJ-ABC) in CIA mice. CEJ-ABC lengthening suggested that oral inoculation of $\mathrm{Pg}$ induced periodontal bone loss. In contrast, preincubation Pg with FimA Ab (Pg/FimA Ab) led to a significantly smaller increase in the CEJ-ABC length (Figures 1a and b). Recent studies showed that infection by Pg disrupts the commensal oral microbiota of the host. This altered oral environment facilitates progression of periodontitis. $^{22}$ Similarly, we found that the number of total oral anaerobic bacteria in the Pg-infected group increased. However, Pg/FimA Ab abrogated this effect on the commensal oral microbiota (Figures $1 \mathrm{c}$ and $\mathrm{d}$ ). These data provide strong evidence that Fim A Ab inhibits periodontitis induced by Pg.

\section{The FimA Ab inhibits Pg adhesion to HGFs}

We next sought to determine whether FimA Ab blocks attachment of Pg to HGFs. HGFs participate in the immune response in periodontal connective tissue. ${ }^{9}$ HGFs were incubated with $\mathrm{Pg}$ or $\mathrm{Pg} / \mathrm{FimA} \mathrm{Ab}$ for $2 \mathrm{~h}$. Scanning electron microscopy revealed that treatment with FimA Ab significantly inhibited attachment of $\mathrm{Pg}$ to the surface of the cells (Figure 2a). In addition, FimA Ab attenuated Pg aggregation, suggesting that Fim $A$ Ab may prevent bacteria biofilm 
formation (Figure 2a). The proportion of Pg binding to HGFs is decreased by approximately three-fold by treating with FimA $\mathrm{Ab}$ (Figure 2b). Transmission electron microscopy also showed that there was more Pg in the proximity of the surface of HGFs than $\mathrm{Pg} / \mathrm{FimA} \mathrm{Ab}$ (Figure 2c). We further analyzed the ability of FimA Ab to prevent Pg attachment by incomplete Freund's adjuvant (IFA). Pg was able to attach to the cell surface; however, $\mathrm{Pg}$ /FimA Ab led to a significant reduction in the number of attached bacteria (Figure 2d). These results suggest that FimA Ab inhibits Pg adhesion and aggregation.

\section{The Fim $A \mathrm{Ab}$ reduces the severity of experimental arthritis induced by $\mathrm{Pg}$ infection}

Previous studies examined whether oral inoculation of CIA mice with Pg ameliorates experimental arthritis. ${ }^{13,14}$ Similar to these studies, we found that oral infected Pg elicited a condition resembling experimental arthritis, including paw swelling and redness. These symptoms were not present in healthy control (wild type) mice and non-inoculated CIA mice. However, mice inoculated with $\mathrm{Pg} / \mathrm{FimA} \mathrm{Ab}$ showed a marked reduction in disease severity (Figure 3a). Pg increased the severity of arthritis by 3 -fold compared with that in mice infected by $\mathrm{Pg} /$ FimA Ab (Figure 3b). Histological evaluation revealed that Pg increased immune cell infiltration, pannus formation, and cartilage erosion in the tarsal joints. These signs were not apparent in mice inoculated with Pg/FimA Ab (Figure 3c). The inflammation and joint destruction scores were also significantly lower in mice treated with $\mathrm{Pg} /$ FimA Ab (Figure 3d). Similar to results with HGFs, electron microscopy and IFA revealed that RASFs treated with $\mathrm{Pg} / \mathrm{FimA} \mathrm{Ab}$ showed a marked reduction in bacterial attachment and invasion as compared with RASFs treated with Pg (Supplementary Figures S1a and b). Taken together, these results suggest that FimA Ab significantly attenuates arthritis by Pg oral infection.

\section{Micro-CT analysis of joint, bone and cartilage destruction}

We next used micro-CT to examine Pg-induced changes in bone density and joint destruction. Mice treated with Pg showed a significant increase in periosteal erosion in the paws, a similar phenotype to that observed in periodontitis-induced extraperiosteal bone loss. Pg/FimA Ab-treated mice showed no periosteal changes (Figures $4 \mathrm{a}$ and $\mathrm{b}$ ). Pg infection accelerated mineral loss at the metatarsal head and from the tarsal bone. In contrast, no mineral bone loss was observed in Pg/FimA Abtreated mice (Figure 4c). Inoculation of $\mathrm{Pg} / \mathrm{FimA} \mathrm{Ab}$ inhibited tibial bone loss compared with that in mice treated with $\mathrm{Pg}$ alone (Figures $4 \mathrm{c}$ and $\mathrm{d}$ ). These observations suggest that Pginduced periodontitis may share pathophysiology with arthritis-mediated bone loss.

Fimbriae are present in the joints of Pg-infected CIA mice Although several reports show that DNA and cell wall components from oral bacteria are present in the synovial fluid of arthritis patients, the precise mechanism underlying the migration of Pg to the joint remains unclear. ${ }^{23-25}$ Here, we found that bacteria fimA was present in the joints of $\mathrm{Pg}$ - infected CIA mice compared with Pg/FimA Ab-infected CIA mice (Figure 5a). As Pg can survive in DCs by inhibiting phagosome-lysosome fusion after phagocytosis ${ }^{26}$ and disarm neutrophils phagocytosis against pathogens,$^{27}$ we hypothesized that Pg exploits the professional phagocytes to migrate into the inflamed joint. To address this hypothesis, we used confocal microscopy to confirm whether fimbriae colocalize with the phagocytes such as DCs, neutrophils and macrophages in the joint of mice. As shown in Figure 5b, confocal microscopy revealed that Pg colocalized with DCs in the tarsal joints of CIA mice. In addition, Pg colocalized with other professional phagocytes such as macrophages and neutrophils (Figures $5 \mathrm{c}$ and d). Interestingly, some Pg fimA-colocalized DCs, macrophages and neutrophils were not only enucleated, but had also released their cellular components along with FimA in the joint (Figures $5 \mathrm{~b}-\mathrm{d}$ ). The DCs, macrophages and neutrophils in the joints of CIA mice treated with $\mathrm{Pg} / \mathrm{FimA} \mathrm{Ab}$ did not contain Pg FimA (Figures 5b-d). Confocal microscopy of Pg-infected CIA mice relatively revealed localization of Pg in the vicinity of joint vascular lesions, indicating that Pg may migrate through the bloodstream toward the inflamed synovial joints (Supplementary Figure S2). Overall, these data suggest that periodontitis-inducing Pg might migrate to arthritic joints by hitching a ride in DCs, macrophages and neutrophils via blood system.

\section{Pg increases synovial inflammation in the joint}

Pg oral infection is significantly related to the occurrence of RA. In addition, we also observed that captured Pg by DCs, macrophages and neutrophils could invade the joint synovial tissues. Therefore, we then confirmed whether inflammatory reaction by bacteria infection was increased in the joint of CIA mice. As TLR2 and TLR4 participate in Pg-induced alveolar bone erosion ${ }^{28}$ we preferentially confirmed the expression of TLR2 and TLR4 using confocal microscopy. The mice infected with Pg showed staining for TLR2 and TLR4 in the joint but not in the joint of the mice infected with Pg/FimA $\mathrm{Ab}$ (Figures $6 \mathrm{a}$ and $\mathrm{b}$ ). These data suggested that by entering the joint, Pg may subvert an inflammatory milieu within the joint. Recent publications show that Pg stimulates proinflammatory cytokine expression such as IL- 8 and tumor necrosis factor- $\alpha$ by several cell lines. ${ }^{26,27,29-31}$ We next sought to examine the expression of inflammatory related proteins by RASFs in the presence of Pg. The cells infected with Pg led to marked induction of proinflammatory cytokines such as IL-8, as well as that of TLR2 and TLR4. We also observed increased levels of matrix metalloproteinase-1 (MMP1) and MMP3 (Figure 6c). Furthermore, Pg-induced inflammatory-related proteins were attenuated by FimA antibody cotreatment (Figure 6c). We then showed that the RASFs treated with crude fimbriae that are chemically isolated from $\mathrm{Pg}$ also increased the expression of inflammatory-related proteins, indicating that fimbriae are required to induce expression of arthritis-promoting cytokines and proteins by synovial fibroblasts. (Figure 6d). Overall, these date suggest that invaded Pg in arthritic joints may induce synovial inflammation and promote chronic arthritis. 
a

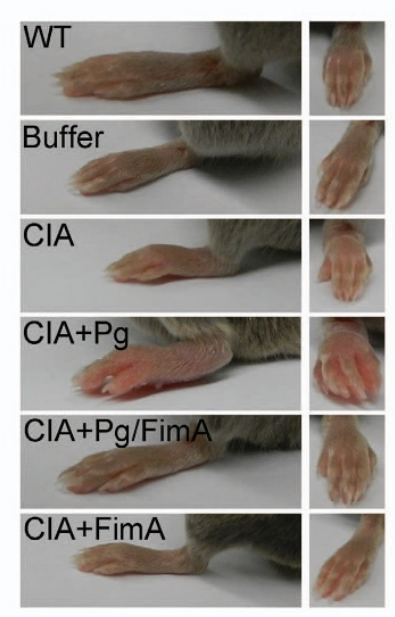

b

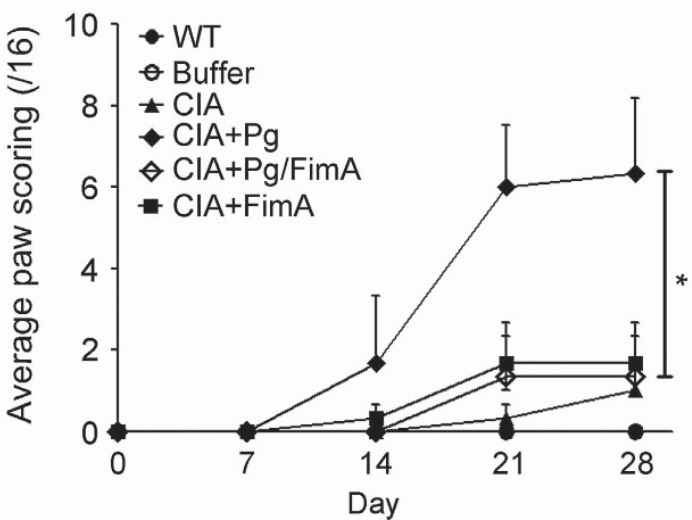

C

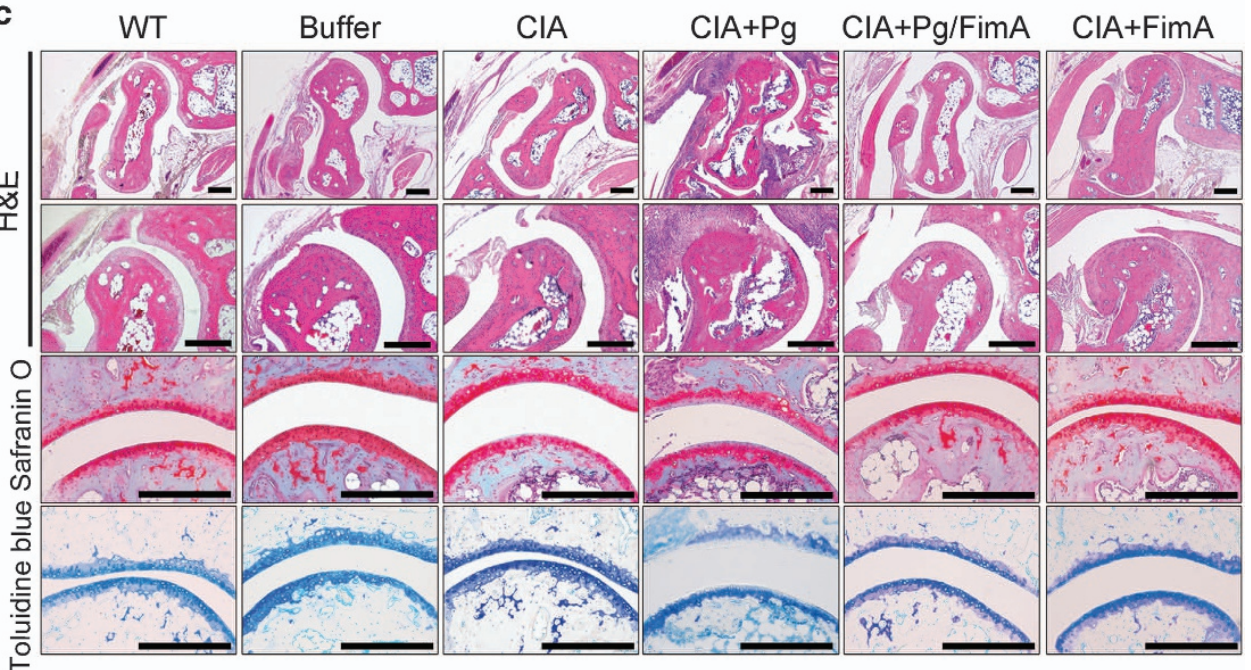

d

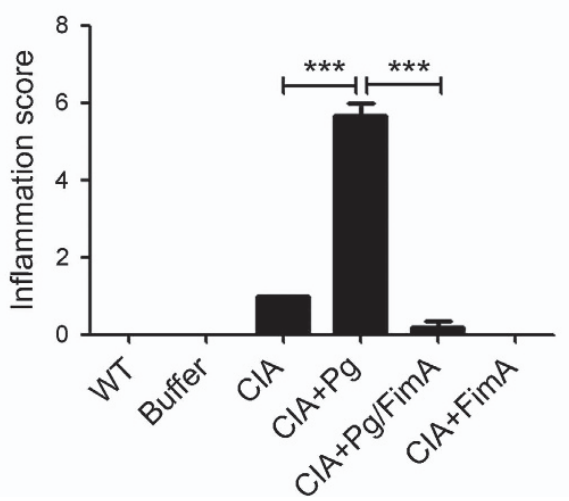

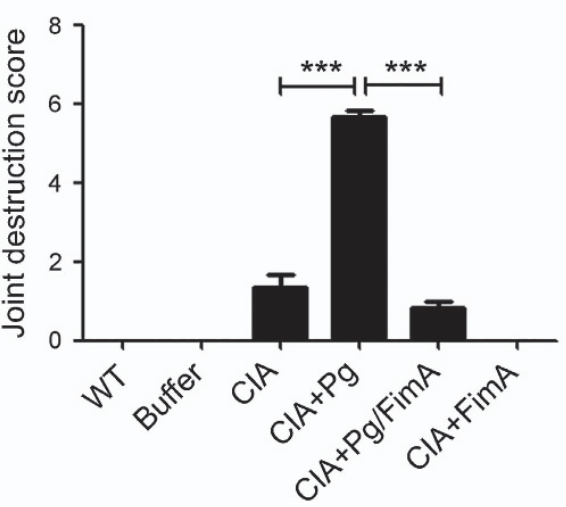

Figure 3 Anti-FimA antibody (aFimA Ab)-treated Porphyromonas gingivalis (Pg) fails to trigger arthritis in collagen-induced arthritis (CIA) mice. (a) Representative hind paw images from each group at 28 days after CIA induction. (b) Clinical paw swelling in each group was scored every week and analyzed using Student's $t$-test $\left({ }^{*} P<0.05\right)$. (c) Representative images of histological change in the joint of ClA mice. Joint sections were stained with hematoxylin and eosin (H\&E) stain, safranin 0 and toluidine blue. Scale bar, $200 \mu \mathrm{m}$. (d) Scoring of histological inflammation and joint bone destruction from the sections. Histological images were scored from three individual researchers. Statistic scoring was analyzed with one-way analysis of variance (ANOVA; ${ }^{* *} P<0.001$ ).

\section{DISCUSSION}

The pathogenesis of Pg-induced periodontitis is involved in the progression of RA; however, the precise mechanism by which Pg exacerbates RA remains unclear. Here, we show that Pg fimbriae are a major virulence factor and contribute to periodontal diseases, including periodontitis. Furthermore, we demonstrate that oral infection by Pg involves in the outbreak of arthritis and exacerbates sequelae associated with 
a

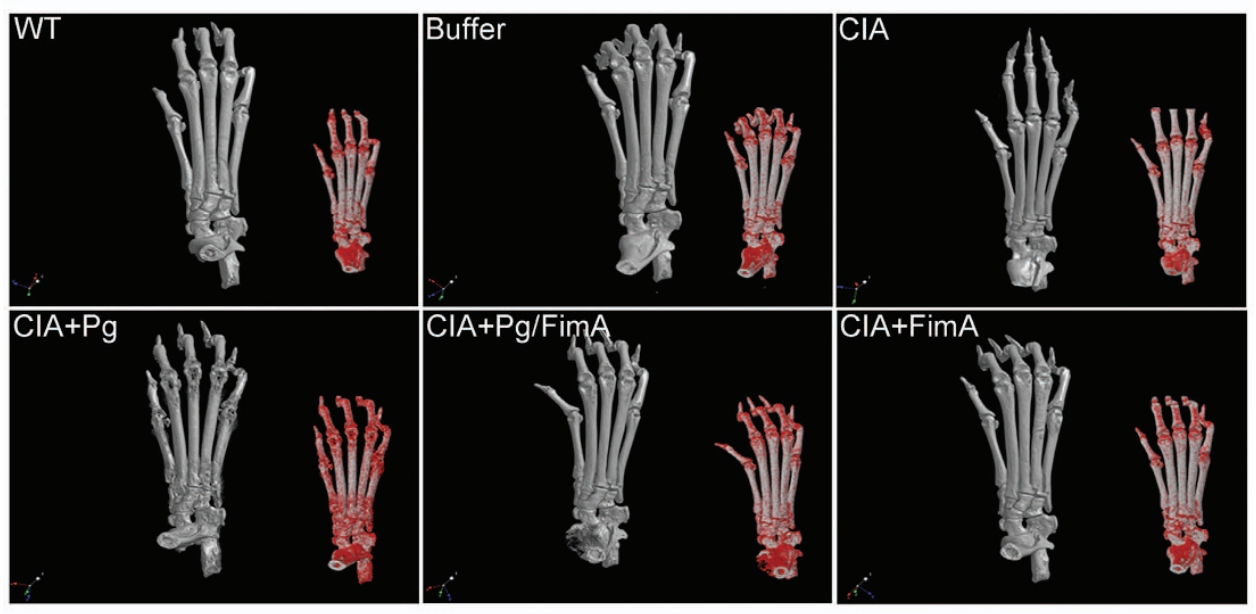

b
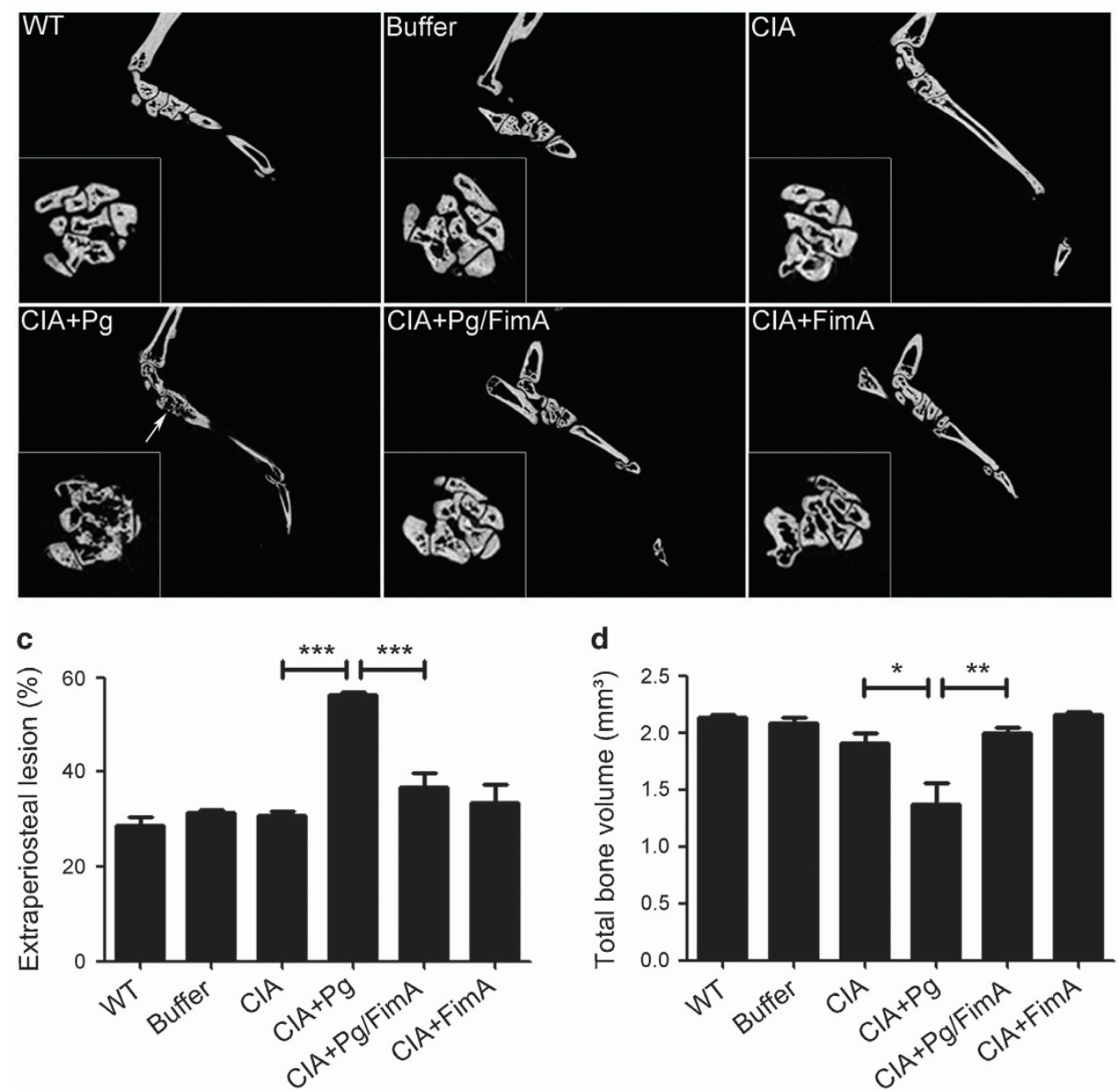

Figure 4 Anti-FimA antibody (aFimA Ab)-treated Porphyromonas gingivalis (Pg) suppresses cartilage erosion and bone destruction in the joint of collagen-induced arthritis (CIA) mice. (a) Representative micro-computed tomography (micro-CT) images of hind paws in each mouse group. The extraperiosteal erosion of the joint is represented in red color in the images. (b) The vertical cross-section represents tarsal joint bone volume. Axial view of the proximal portion (arrow) of tarsal bones (inserts). (c) Quantification of total extraperiosteal erosion volume of hind paws. (d) Quantification of total bone volume of hind paws. Statistical analysis was performed using one-way analysis of variance (ANOVA; $n=3,{ }^{*} P<0.05,{ }^{*} P<0.01$ and ${ }^{* * *} P<0.001$ ). 
a

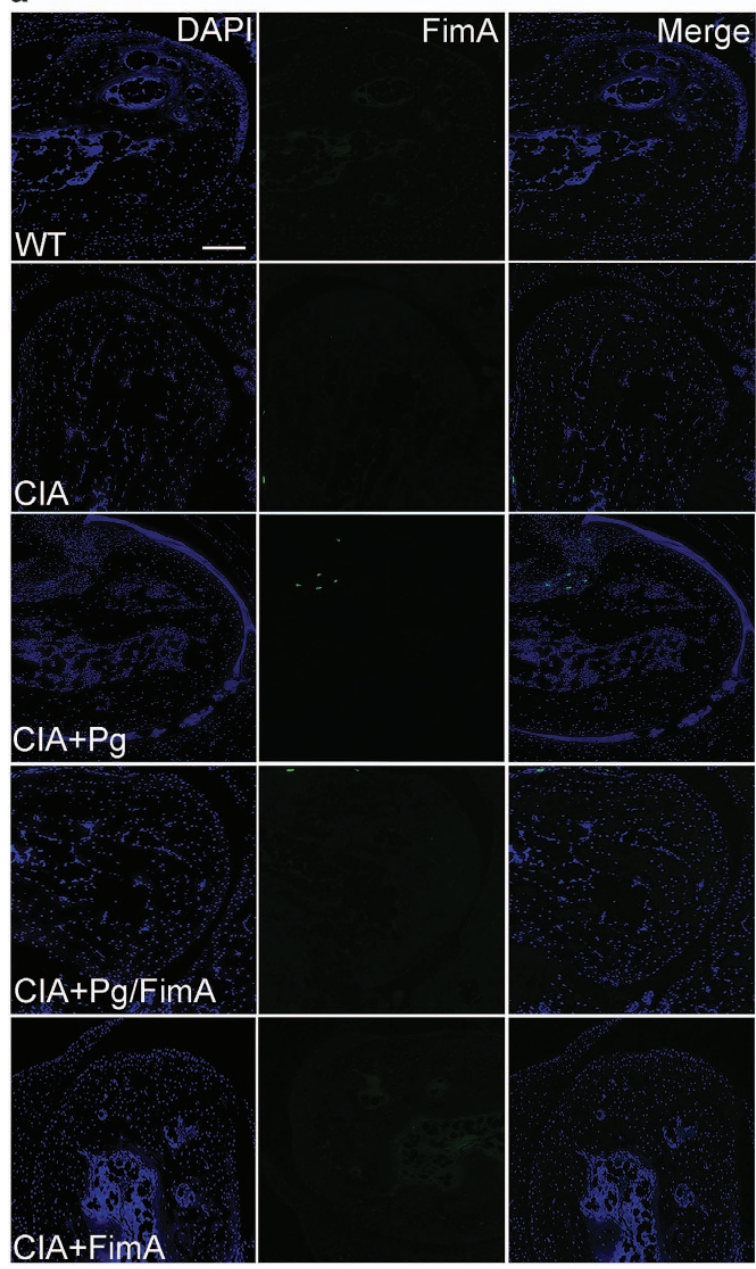

b
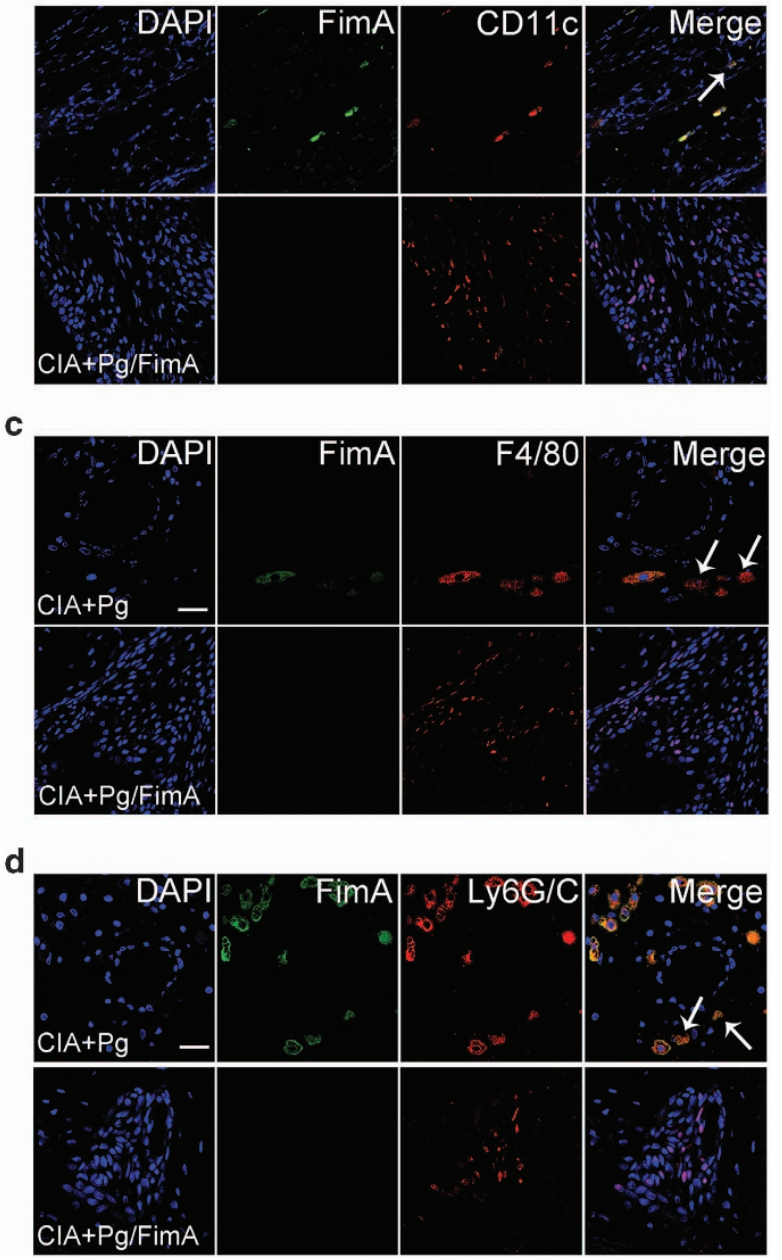

Figure 5 Oral infected Porphyromonas gingivalis (Pg) can migrate into the inflamed joint. (a) Detection of FimA (green) in the joint of collagen-induced arthritis (CIA) mice by confocal microscopy. Scale bar, $100 \mu \mathrm{m}$. (b-d) Immunohistochemical double staining of dendritic cells (CD11c: red) (b), macrophages (F4/80: red) (c) and neutrophils (Ly6G/C: red) (d), respectively, and FimA (green) in the joint section of CIA mice. Cell nuclei are stained with 4',6-diamidino-2-phenylindole (DAPI; blue). Scale bar, $100 \mu \mathrm{m}$. Arrows indicate the enucleated cells.

experimental arthritis, including increased synovial cell invasion, joint bone and cartilage destruction and increased expression of proinflammatory cytokines such as IL-8. Interestingly, FimA Ab effectively ameliorates Pg-aggravated experimental arthritis. We also observe that orally infected Pg probably migrates toward arthritic joints by exploiting DCs, macrophages and neutrophils and result in rheumatic inflammation such as synovitis and cartilage erosion.

Several studies have shown that a major fimbriae-specific mutant of Pg is unable to invade gingival epithelial cells and cause periodontal bone loss. ${ }^{11,32,33}$ Moreover, treatment of buccal epithelial cells with an anti-fimbriae $\mathrm{Ab}$ significantly attenuates bacterial adhesion. ${ }^{34}$ Thus, it could be speculated that Pg fimbriae play an important role in the development of periodontitis and subsequent RA progression. The CIA mice generated in the present study did not receive a second immunization with CII; this enabled us to examine subtle changes in arthritis severity in vivo. This strategy appears unfavorable in terms of arthritis induction, but objectively reflects the approach taken in a 'two hit' model study. ${ }^{35}$ Compared with Pg, infection with Pg/FimA Ab led to a marked reduction in alveolar bone loss and promoted a dysbiotic oral microbiota in CIA mice. These results are consistent with those presented in a study showing that Pg infection triggers changes in the commensal oral microbiota and induces inflammationmediated periodontal bone loss. ${ }^{22}$ Furthermore, we observed that mice exposed to Pg show not only arthritic symptoms such as paw swelling and redness, but also signs of synovitis such as pannus formation and bone destruction. None of these were observed in mice treated with $\mathrm{Pg} / \mathrm{FimA} \mathrm{Ab}$. In addition, only Pg-inoculated normal mice showed that there were no signs of arthritis (data not shown). Based on the previously published data, oral-infected Pg might migrate into joint cavity along the signal such as inflammatory responses. ${ }^{35}$ Thus, for mice with no inflammatory responses in the joints, only periodontitis might not produce a chain reaction like arthritis. 


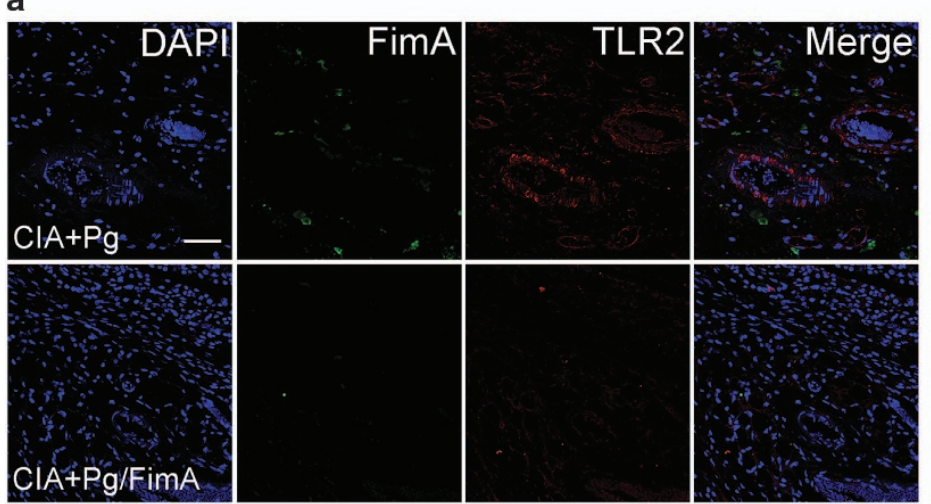

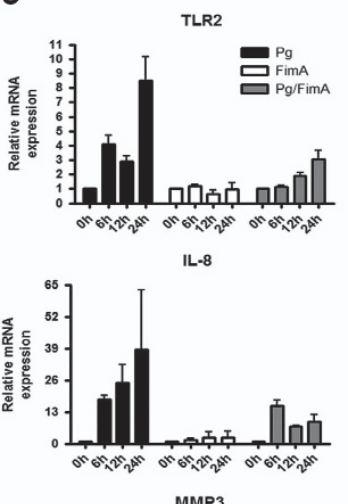

MMP3

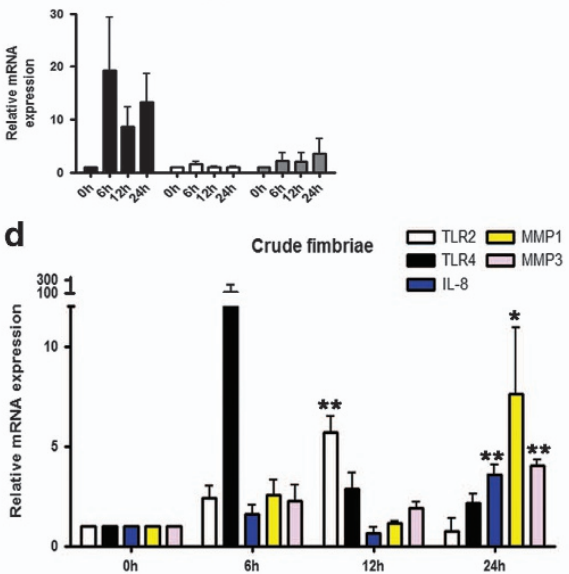

b

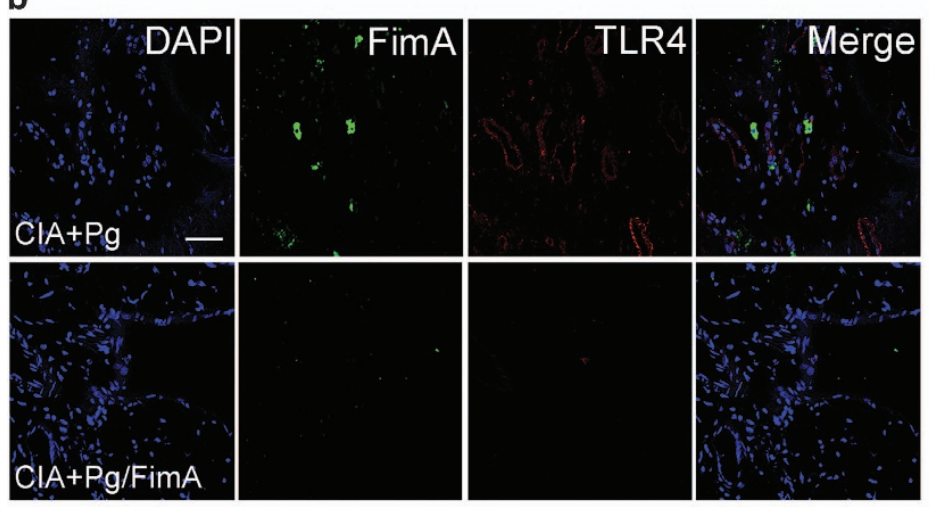

Figure 6 Porphyromonas gingivalis (Pg) is involved in synovial inflammation. (a, b) Double immunofluorescence staining of Toll like
receptor-2 (TLR2) (a; red) or TLR4 (b; red) and FimA (green) in the joint of collagen-induced arthritis (CIA) mice. Cell nuclei were stained with 4',6-diamidino-2-phenylindole (DAPI; blue). Scale bar, $100 \mu \mathrm{m}$. (c, d) Rheumatoid arthritis synovial fibroblast (RASF) was treated with $\mathrm{Pg}$ (c) or crude fimbriae (d) and incubated for various time points. The RNA expression levels of synovial inflammation-related cytokines and proteins were detected by real-time PCR. Statistical analysis was performed using one-way analysis of variance (ANOVA; $n=3$, ${ }^{*} P<0.05$ and $\left.{ }^{* *} P<0.01\right)$.

Previous clinical studies showed that RA patients often have periodontitis. $^{3-6}$ Conversely, patients with periodontitis are more likely to develop RA. ${ }^{6,7} \mathrm{RA}$ is associated with increased levels of citrullinated protein that are generated by peptidylarginine deiminases (PADs) that convert arginine residues to citrulline residues. ${ }^{36} \mathrm{RA}$ patients with anti-citrullinated protein antibodies show a relatively high rate of alveolar bone loss, a hallmark of periodontitis. ${ }^{37}$ Of note, $\mathrm{Pg}$ is the only bacterium that produces a PAD enzyme (Pg PAD or PPAD). Although there are differences in sequence between PPAD and human $\mathrm{PAD}, \mathrm{PPAD}$ can also induce citrullinated proteins such as fibrin, fibrinogen, $\alpha$-enolase and vimentin in patients with RA. ${ }^{36,38-40}$ A previous study showed that, unlike normal Pg, PPAD-null Pg did not elicit arthritis in CIA mice. ${ }^{41}$ Thus, increased citrullination by PAD and the subsequent induction of anti-citrullinated protein antibodies are the main drivers of arthritis caused by Pg. However, DNA and bacterial cell wall constituents, such as peptidoglycans, derived from oral bacteria are present in the joints and synovial fluid of RA patients. $^{24,25,42}$ Therefore, we speculated that orally infected Pg may penetrate the joints of RA patients, where it promotes disease exacerbation. Here, we identified Pg in the tarsal joints of Pg-inoculated CIA mice, suggesting that periodontitis increases dissemination of bacteria to the joints and contributes to RA progression.

To survive in the harsh milieu within a host, Pg suppresses autophagy after phagocytosis by DCs; the bacterium then migrates to distant organs such as blood vessels, brain and placenta. ${ }^{26,43}$ Similarly, we observed colocalization of Pg and DCs in the tarsal joints of Pg-infected CIA mice; this was rarely observed in the joints of mice inoculated with Pg/FimA Ab. Moreover, orally inoculated $\mathrm{Pg}$ also colocalized with macrophages and neutrophils. These results suggest that Pg might migrate from the oral cavity to the joints by hitching a ride inside phagocytes. Compared with $\mathrm{Pg} / \mathrm{FimA} \mathrm{Ab}$, infection with $\mathrm{Pg}$ resulted in significantly greater numbers of enucleated phagocytes and increased phagocyte death in CIA mice, suggesting that $\mathrm{Pg}$ might come into direct contact with rheumatoid synovial membrane and cartilage after being released from phagocytes. Thus, our results indicate that $\mathrm{Pg}$ might migrate to the arthritic joint, where it plays a role in synovial inflammation. Interestingly, several studies reported the absence of live bacteria from the joints of Pg-infected mice ${ }^{24,41,42}$ however, we detected the presence of $\mathrm{Pg}$ in the 
joints of CIA mice by staining with specific FimA Ab. Clearly, though, we were not able to determine whether the bacteria were alive.

Synovial fibroblasts in arthritic joints release proinflammatory cytokines and promote cartilage erosion by secreting MMPs. ${ }^{1}$ We thereby hypothesized that Pg might be involved in arthritic inflammation after a direct migration into the inflamed joint. Our in vitro studies showed that treatment of RASFs with Pg lead to a significant increase in IL-8 levels, both of which recruit immune cells and induce production of MMP1 and MMP3, thereby inducing pathologic inflammation. Expression of TLR2 and TLR4 was also increased in Pginfected RASFs. Interestingly, FimA Ab-treated Pg was unable to induce inflammatory-related proteins such as TLR2, TLR4, IL-8, MMP1 and MMP3. Furthermore, treatment of RASFs with crude fimbriae that were isolated from $\mathrm{Pg}$ also induced TLR2, TLR4, IL-8, MMP1 and MMP3. These results lead to the conclusion that migration of orally infected $\mathrm{Pg}$ can directly accelerate synovial fibroblasts activation and induce arthritic inflammation in the joints.

In conclusion, our findings suggest that Pg-induced periodontitis increases the incidence and severity of RA in an experimental mouse model. However, these effects are ameliorated when $\mathrm{Pg}$ is pretreated with FimA Ab. This is the first study to report that orally infected Pg directly migrates to the joints via DCs, macrophages and neutrophils, where it is released and contributes to synovial inflammation. The data presented herein suggest that treating periodontitis may alleviate or prevent the progression of RA.

\section{CONFLICT OF INTEREST}

The authors declare no conflict of interest.

\section{ACKNOWLEDGEMENTS}

We thank Dr Tae-Ho Kwon for providing the anti-FimA antibodies. This work was supported by a grant from the Basic Science Research Program through the National Research Foundation of Korea (NRF) funded by the Ministry of Science, ICT \& Future Planning (2013R1A1A1076125), a grant from Advanced Production Technology Development Program, Ministry for Food, Agriculture, Forestry and Fisheries (312037-05) and a grant of the Korea Healthcare Technology R\&D project, Ministry for Health, Welfare \& Family Affairs, Republic of Korea (HI16C2177).

\section{PUBLISHER'S NOTE}

Springer Nature remains neutral with regard to jurisdictional claims in published maps and institutional affiliations.

1 McInnes IB, Schett G. The pathogenesis of rheumatoid arthritis. N Eng/ J Med 2011; 365: 2205-2219.

2 Persson GR. Rheumatoid arthritis and periodontitis inflammatory and infectious connections. Review of the literature. J Oral Microbiol 2012; 4: 10.

3 Wolff B, Berger T, Frese C, Max R, Blank N, Lorenz H-M et al. Oral status in patients with early rheumatoid arthritis: a prospective, case-control study. Rheumatology 2014; 53: 526-531.
4 Joseph R, Rajappan S, Nath SG, Paul BJ. Association between chronic periodontitis and rheumatoid arthritis: a hospital-based case-control study. Rheumatol Int 2013; 33: 103-109.

5 Pischon N, Pischon T, Kröger J, Gülmez E, Kleber B-M, Bernimoulin J-P et al. Association among rheumatoid arthritis, oral hygiene, and periodontitis. J Periodontol 2008; 79: 979-986.

6 Smit M, Westra J, Vissink A, Doornbos-van der Meer B, Brouwer E, van Winkelhoff AJ. Periodontitis in established rheumatoid arthritis patients: a cross-sectional clinical, microbiological and serological study. Arthritis Res Ther 2012; 14: R222.

7 Mercado F, Marshall RI, Klestov AC, Bartold PM. Is there a relationship between rheumatoid arthritis and periodontal disease? J Clin Periodontol 2000; 27: 267-272.

8 Enersen M, Nakano K, Amano A. Porphyromonas gingivalis fimbriae. J Oral Microbiol 2013; 5.

9 McCulloch CA, Bordin S. Role of fibroblast subpopulations in periodontal physiology and pathology. J Periodontal Res 1991; 26: 144-154.

10 Hamada N, Watanabe K, Sasakawa C, Yoshikawa M, Yoshimura F, Umemoto T. Construction and characterization of a fimA mutant of Porphyromonas gingivalis. Infect Immun 1994; 62: 1696-1704.

11 Malek R, Fisher J, Caleca A, Stinson M, Van Oss C, Lee J et al. Inactivation of the Porphyromonas gingivalis fimA gene blocks periodontal damage in gnotobiotic rats. J Bacteriol 1994; 176: 1052-1059.

12 Hanazawa S, Murakami Y, Hirose K, Amano S, Ohmori Y, Higuchi H et al. Bacteroides (Porphyromonas) gingivalis fimbriae activate mouse peritoneal macrophages and induce gene expression and production of interleukin-1. Infect Immun 1991; 59: 1972-1977.

13 Marchesan JT, Gerow EA, Schaff R, Taut AD, Shin S-Y, Sugai J et al. Porphyromonas gingivalis oral infection exacerbates the development and severity of collagen-induced arthritis. Arthritis Res Ther 2013; 15: 1-13.

14 Cantley MD, Haynes DR, Marino V, Bartold PM. Pre-existing periodontitis exacerbates experimental arthritis in a mouse model. J Clin Periodontol 2011; 38: 532-541.

15 Bartold PM, Marino V, Cantley M, Haynes DR. Effect of Porphyromonas gingivalis-induced inflammation on the development of rheumatoid arthritis. J Clin Periodontol 2010; 37: 405-411.

16 Koh EM, Kim J, Kim TG, Moon JH, Oh JH, Lee JY et al. Cloning and characterization of heavy and light chain genes encoding the FimA-specific monoclonal antibodies that inhibit Porphyromonas gingivalis adhesion. Microbiol Immunol 2011; 55: 199-210.

17 Koh E-M, Kim J, Lee J-Y, Kim T-G. Production of monoclonal antibodies specific to FimA of Porphyromonas gingivalis and their inhibitory activity on bacterial binding. Immune Netw 2009; 9: 203-207.

$18 \mathrm{Li} \mathrm{CH}$, Amar S. Morphometric histomorphometric, and microcomputed tomographic analysis of periodontal inflammatory lesions in a murine model. J Periodontol 2007; 78: 1120-1128.

19 Jeffrey JY, Ruddy MJ, Wong GC, Sfintescu C, Baker PJ, Smith JB et al. An essential role for IL-17 in preventing pathogen-initiated bone destruction: recruitment of neutrophils to inflamed bone requires IL-17 receptordependent signals. Blood 2007; 109: 3794-3802.

20 Bigbee CL, Gonchoroff DG, Vratsanos G, Nadler SG, Haggerty HG, Flynn JL. Abatacept treatment does not exacerbate chronic Mycobacterium tuberculosis infection in mice. Arthritis Rheum 2007; 56: 2557-2565.

21 Kim Y, Yi H, Jung H, Rim YA, Park N, Kim J et al. A dual target-directed agent against interleukin- 6 receptor and tumor necrosis factor $\alpha$ ameliorates experimental arthritis. Sci Rep 2016; 6: 20150.

22 Hajishengallis G, Liang S, Payne MA, Hashim A, Jotwani R, Eskan MA et al. Low-abundance biofilm species orchestrates inflammatory periodontal disease through the commensal microbiota and complement. Cell Host Microbe 2011; 10: 497-506.

23 Moen K, Brun JG, Eribe ER, Olsen I, Jonsson R. Oral bacterial DNAs in synovial fluids of arthritis patients. Microb Ecol Health Dis 2005; 17: 2-8.

24 Moen K, Brun J, Valen M, Skartveit L, Eribe E, Olsen I et al. Synovial inflammation in active rheumatoid arthritis and psoriatic arthritis facilitates trapping of a variety of oral bacterial DNAs. Clin Exp Rheumatol 2006; 24: 656-663.

25 Ineke M, Heijden BW, Ilja T, Ingrid AS, Schouls L, Maarten PH et al. Presence of bacterial DNA and bacterial peptidoglycans in joints of patients with rheumatoid arthritis and other arthritides. Arthritis Rheum 2000; 43: 593-598.

26 El-Awady AR, Miles B, Scisci E, Kurago ZB, Palani CD, Arce RM et al. Porphyromonas gingivalis evasion of autophagy and intracellular killing by human myeloid dendritic cells involves DC-SIGN-TLR2 crosstalk. PLoS Pathog 2015; 11: e1004647. 
27 Maekawa T, Krauss JL, Abe T, Jotwani R, Triantafilou M, Triantafilou K et al. Porphyromonas gingivalis manipulates complement and TLR signaling to uncouple bacterial clearance from inflammation and promote dysbiosis. Cell Host Microbe 2014; 15: 768-778.

28 Lin J, Bi L, Yu X, Kawai T, Taubman MA, Shen B et al. Porphyromonas gingivalis exacerbates ligature-induced, RANKL-dependent alveolar bone resorption via differential regulation of Toll-like receptor 2 (TLR2) and TLR4. Infect Immun 2014; 82: 4127-4134.

29 Takahashi Y, Davey M, Yumoto H, Gibson Iii FC, Genco CA. Fimbriadependent activation of pro-inflammatory molecules in Porphyromonas gingivalis infected human aortic endothelial cells. Cell Microbiol 2006; 8: 738-757.

30 Walter C, Zahlten J, Schmeck B, Schaudinn C, Hippenstiel S, Frisch E et al. Porphyromonas gingivalis strain-dependent activation of human endothelial cells. Infect Immun 2004; 72: 5910-5918.

31 Liu J, Tang X, Li C, Pan C, Li Q, Geng F et al. Porphyromonas gingivalis promotes the cell cycle and inflammatory cytokine production in periodontal ligament fibroblasts. Arch Oral Biol 2015; 60: 1153-1161.

32 Weinberg A, Belton CM, Park Y, Lamont RJ. Role of fimbriae in Porphyromonas gingivalis invasion of gingival epithelial cells. Infect Immun 1997; 65: 313-316.

33 Njoroge T, Genco RJ, Sojar HT, Hamada N, Genco CA. A role for fimbriae in Porphyromonas gingivalis invasion of oral epithelial cells. Infect Immun 1997; 65: 1980-1984.

34 Isogai H, Isogai E, Yoshimura F, Suzuki T, Kagota W, Takano K. Specific inhibition of adherence of an oral strain of Bacteroides gingivalis 381 to epithelial cells by monoclonal antibodies against the bacterial fimbriae. Arch Oral Biol 1988; 33: 479-485.

35 Golub L, Payne J, Reinhardt R, Nieman G. Can systemic diseases co-induce (not just exacerbate) periodontitis? A hypothetical "two-hit" model. J Dent Res 2006; 85: 102-105.

36 Mangat P, Wegner N, Venables PJ, Potempa J. Bacterial and human peptidylarginine deiminases: targets for inhibiting the autoimmune response in rheumatoid arthritis? Arthritis Res Ther 2010; 12: 209.

37 Gonzalez SM, Payne JB, Yu F, Thiele GM, Erickson AR, Johnson PG et al. Alveolar bone loss is associated with circulating anti-citrullinated protein antibody (ACPA) in patients with rheumatoid arthritis. J Periodontol 2015; 86: 222-231.

38 Wegner N, Wait R, Sroka A, Eick S, Nguyen KA, Lundberg K et al. Peptidylarginine deiminase from Porphyromonas gingivalis citrullinates human fibrinogen and $\alpha$-enolase: implications for autoimmunity in rheumatoid arthritis. Arthritis Rheum 2010; 62: 2662-2672.

39 Masson-Bessière C, Sebbag M, Girbal-Neuhauser E, Nogueira L, Vincent C, Senshu $T$ et al. The major synovial targets of the rheumatoid arthritisspecific antifilaggrin autoantibodies are deiminated forms of the $\alpha$-and $\beta$ chains of fibrin. J Immunol 2001; 166: 4177-4184.

40 Mathsson L, Mullazehi M, Wick MC, Sjöberg O, Van Vollenhoven R, Klareskog $L$ et al. Antibodies against citrullinated vimentin in rheumatoid arthritis: higher sensitivity and extended prognostic value concerning future radiographic progression as compared with antibodies against cyclic citrullinated peptides. Arthritis Rheum 2008; 58: 36-45.

41 Maresz KJ, Hellvard A, Sroka A, Adamowicz K, Bielecka E, Koziel J et al. Porphyromonas gingivalis facilitates the development and progression of destructive arthritis through its unique bacterial peptidylarginine deiminase (PAD). PLoS Pathog 2013; 9: e1003627.

42 Martinez-Martinez RE, Abud-Mendoza C, Patiño-Marin N, Rizo-Rodríguez JC, Little JW, Loyola-Rodríguez JP. Detection of periodontal bacterial DNA in serum and synovial fluid in refractory rheumatoid arthritis patients. J Clin Periodontol 2009; 36: 1004-1010.

43 Carrion J, Scisci E, Miles B, Sabino GJ, Zeituni AE, Gu Y et al. Microbial carriage state of peripheral blood dendritic cells (DCs) in chronic periodontitis influences DC differentiation, atherogenic potential. J Immunol 2012; 189: 3178-3187.

This work is licensed under a Creative Commons Attribution-NonCommercial-NoDerivs 4.0 International License. The images or other third party material in this article are included in the article's Creative Commons license, unless indicated otherwise in the credit line; if the material is not included under the Creative Commons license, users will need to obtain permission from the license holder to reproduce the material. To view a copy of this license, visit http://creativecommons.org/licenses/by-nc-nd/4.0/

(C) The Author(s) 2018

Supplementary Information accompanies the paper on Experimental \& Molecular Medicine website (http://www.nature.com/emm) 